\title{
Investigation Type of Reasoning of Biology Prospective Teachers on Controversial Issues of the Theory of Evolution
}

\author{
${ }^{1}$ Laras Firdaus, ${ }^{1 *}$ Masiah, ${ }^{2}$ Ibrohim, ${ }^{2}$ Sri Rahayu Lestari \\ ${ }^{1}$ Biology Education Departement, Fakulty of Science, Technology, and Applied, Mandalika \\ Universtiy of Education. J1. Pemuda No. 59A Mataram, Indonesia \\ ${ }^{2}$ Biology Department, Universitas Negeri Malang, J1. Semarang No.5, Malang, Jawa Timur \\ 65145, Indonesia
}

*Corresponding Author e-mail: masiah@ikipmataram.ac.id

Received: September 2021; Revised: November 2021; Published: December 2021

\begin{abstract}
This study is a descriptive study that aims to explain the type of reasoning of biology prospective teachers on controversial issues of the theory of evolution. As much 26 prospective biology teachers at the Mandalika University of Education as participants. All participants are students who regularly program evolution courses in even semesters (2020/2021). A total of 3 open-ended question based on socioscientific issues (SSI) were used to obtain information about the type of reasoning of biology prospective teachers. The data analysis process was carried out descriptively, and based on the results of the study, that the type of reasoning of prospective biology teacher students was dominated by the type of reasoning based on religious beliefs and intuitive reasoning. These results indicate that the student biology prospective teachers not only conflict between religious beliefs and the theory of evolution, but also do not understand the concepts on the theory of evolution. Referring to the results of this study, further research is recommended to examine the acceptance or understanding, and beliefs of teachers, both in middle and high schools on the theory of evolution.
\end{abstract}

Keywords: Type of reasoning; socio-scientific issues; theory of evolution

How to Cite: Firdaus, L., Masiah, M., Ibrohim, I., \& Lestari, S. (2021). Investigation Type of Reasoning of Biology Prospective Teachers on Controversial Issues of The Theory of Evolution. Prisma Sains : Jurnal Pengkajian Ilmu dan Pembelajaran Matematika dan IPA IKIP Mataram, 9(2), 336-342. doi:https://doi.org/10.33394/j-ps.v9i2.4164

https://doi.org/10.33394/j-ps.v9i2.4164

Copyright $\odot$ 2021, Firdaus et al This is an open-access article under the CC-BY License. (c) (i)

\section{INTRODUCTION}

National Research Council; Ruiz-Primo; Schunn and Anderson, stated that the main goal in higher education is to improve students' conceptual understanding and mastery of general skills, and scientific reasoning is one of these general skills (Ding, Wei, \& Mollohan, 2014). As a very important skill, the initial conception of scientific reasoning skills can be traced through Piaget's cognitive development theory of formal operational reasoning, including scientific reasoning (Opitz, Heene, \& Fischer, 2017). Later in its development, there was a debate among experts regarding scientific skills, whether they can be taught (trained) or not. Coletta \& Phillips; Fencl; Klahr, Zimmerman and Jirout; Kuhn; Moore and Rubbo; Nieminen, Savinainen, and Viiri; Schauble, stated that there is mutual agreement in the educational community that scientific reasoning skills are skills that can be taught or trained (Ding, Wei, \& Mollohan, 2014).

Daempfle states that reasoning skills are skills that allow students to be involved in problem solving and make logical conclusions (Setambah, 2018), and in general scientific reasoning is a type of reasoning that helps students to develop hypotheses, especially about 
how things work. In the reasoning process, students' prior knowledge is associated with the observation process they do. If the observations do not match his initial knowledge, he must revise his initial knowledge into appropriate knowledge, or what is called scientific knowledge (Zulkipli et al., 2020). Simon; Kind, defines scientific reasoning as a problemsolving process that includes critical thinking skills in relation to content, epistemic, and procedural knowledge (Barz \& Cadariu, 2016), while Lawson defines scientific reasoning as the ability to show patterns of formal operations, including identification and control. variable, proportional reasoning, hypothetical-deductive reasoning, correlational reasoning, and combination reasoning (Manwaring et al., 2018). Fischer shows that scientific reasoning skills consist of several components, including problem identification, formulating hypotheses, designing experimental designs, evaluating evidence, drawing conclusions, and communicating them (Opitz, Heene, \& Fischer, 2017).

Previous studies have shown that students who have scientific reasoning abilities have consistent beliefs about scientific consensus (Cavojová \& Ersoy, 2019). Bao et al stated that scientific reasoning ability is correlated with cognitive abilities which include rational thinking, judgment, and decision making (Zulkipli et al., 2020). Bell and Lederman stated that biology students who used socio scientific issues (SSI) had higher levels of scientific reasoning (Saad et al., 2017). Han stated that the study of scientific reasoning abilities helps students in solving problems in everyday life (Abate, Michael, \& Angell, 2020). Just like Han, Koerber and Mayer showed that scientific reasoning skills are highly correlated with students' intelligence and language skills (Osterhaus, Koerber, \& Sodian, 2020).

Dobzhansky and Coyne stated that the theory of evolution is one of the most fundamental theories in the discipline of biology. As a mature theory, the theory of evolution tries to explain the evolution of organisms and their differences from previous organisms (Gefaell et al., 2020), but even so, evolutionary debates or controversies still occur today. Sinatra; Hermann, states that evolution is different from other topics in biology, such as genetics and physiology. The difference lies in the level of acceptance, students are more accepting of genetics or physiology rather then evolution, because they study it as something real, while evolution is considered as something that is contrary to religious beliefs (Barnes et al., 2021).

Antolin and Herbers stated that one of the factors related to students' understanding of the concept of evolution is that most students have a religious tendency towards scientific theories (Bickmore et al., 2009), and nevertheless reasoning about biological evolution is based on intuitive thinking or scientific reasoning (Cheryl-To, Tenenbaum, \& Hogh, 2017). Shtulman and Schulz; Coley and Tanner, add that the available evidence suggests that the challenges in understanding evolution are rooted in deeply held intuitive thinking rather than the complexity of the concept of biology itself (Richard, Coley, \& Tanner, 2017). Cognitive construction is an informal and intuitive way of thinking about the world, and perhaps such a way or process of thinking is composed of a set of assumptions, types of explanations, or even tendencies toward other types of reasoning (Coley \& Tanner, 2015; Coley et al., 2017). Mohan; Hartley; Gunckel, explained that students' intuitive reasoning patterns are reasoning that includes misconceptions, and this reasoning pattern is one of the characteristics of students' reasoning (Coley \& Tanner, 2015), or intuitive reasoning patterns are reasoning related to misconceptions of biological concepts, which intuitive reasoning can lead to inappropriate conclusions when applied in a scientific context (Richard, Coley, \& Tanner, 2017).

Based on the description above, in this study, the reasoning patterns of prospective teachers are classified into three categories (reasoning based on religious beliefs, intuitive reasoning, and scientific reasoning). In this study, what is meant by scientific reasoning is that the reasoning given by prospective teachers is logical reasoning (facts that are studied or deep thought about in depth so as to form logical reasoning), reasoning is built on evidence (examples), shows cause and effect accompanied by a rational explanation. The purpose of 
this study was to explain the type of reasoning of prospective biology teacher students. The results of this research are then used as data to develop the learning process, especially learning in the evolution course.

\section{METHOD}

This research is a descriptive study, then the 26 participants involved in this research, that are all biology prospective teachers who regularly program evolution courses in even semesters (2020/2021) at the Faculty of Science, Technology, and Applied, Mandalika University of Education. In evolution there are several controversial issues, such as the controversy between evolution and religion. A total of 3 open-ended questions based on socio-scientific issues (SSI) were used to obtain data on the type of reasoning of biology prospective teachers. Sadler and Zeidler; Sadler, stated that SSI covers a variety of controversial social issues related to science (Cebesoy, 2020). The data were analyzed based on the response or reasoning given by the respondents, whether reasoning based on religious beliefs, intuitive thinking, or scientific reasoning.

\section{RESULT AND DISCUSSIONS}

Mandalika University of Education is a university with diverse student characteristics, both in terms of religion and culture. There are several definitions of religious belief, which one that religious belief is related to the function of religious belief in life (Bautista, Escobar, \& Miranda, 2017), that religious belief is related to the function of religious beliefs in life, but in the controversy between evolution and religion, acceptance and understanding of evolution is influenced by several factors, such as knowledge about evolution itself and religious beliefs (Arthur, 2013). However, several studies have shown that religious belief is related to religious practices, and only educational background is positively correlated with knowledge (Torkar \& Sorgo, 2020). Then if we pay attention to the type of reasoning of prospective biology teacher students as shown on the Table 1, which reasoning is dominated by reasoning based on religious beliefs and intuitive reasoning. These results indicate that there is a conflict between religious beliefs with the theory of evolution.

Table 1. Proportion of the type of reasoning of prospective biology teacher students

\section{Type of reasoning}

Question

$\begin{array}{ccc}\text { Religious } & \text { Intuitif } & \begin{array}{c}\text { Scientific } \\ \text { belief }(\mathrm{N})\end{array} \\ (\mathrm{N}) & \begin{array}{c}\text { reasoning } \\ (\mathrm{N})\end{array}\end{array}$

1. Evolution is one of the important theories in the discipline of biology, without evolution perhaps phenomena or concepts in biology are difficult to understand. Evolution as a valid and scientific theory, in its development continues to get criticism, and even the controversy about evolution continues to this day. One of the popular controversies is that most people assume that the theory of evolution is a theory that relates or explains the origin of life. How do you feel about what most people think about the theory of evolution?

2. Then on other occasions, evolution is not only considered as a theory that explains the origin of life, but also evolution is considered a theory that is difficult to prove, or the theory of evolution is a theory that is not scientifically proven. What is your opinion about this opinion or assumption?

3. Darwin in his theory of evolution stated that 
Type of reasoning

\begin{tabular}{llll} 
Question & $\begin{array}{l}\text { Religious } \\
\text { belief }(\mathrm{N})\end{array}$ & $\begin{array}{c}\text { Intuitif } \\
(\mathrm{N})\end{array}$ & $\begin{array}{c}\text { Scientific } \\
\text { reasoning } \\
(\mathrm{N})\end{array}$ \\
\hline $\begin{array}{l}\text { organisms, including human have a common } \\
\text { ancestor. What do you think about Darwin's opinion } \\
\text { about the common ancestor? }\end{array}$ & & \\
\hline
\end{tabular}

The conflict between religious beliefs and the theory of evolution was also shown by students in Utah (Barnes, et al., 2019), also occurred in biology students (Barnes et al., 2020). Hokayem and BouJaoude (2008); Richard, Coley, and Tanner (2017), that reasoning based on religious beliefs and intuitive reasoning is reasoning related to misconceptions about biological content, so it can be stated that biology prospective teachers not only showed the conflict between their religious beliefs with theory of evolution, but also indicate that biology prospective teachers have misconceptions about the concept of evolution itself, biology prospective teachers do not understand about the content of the theory of evolution.

As much 68\% of Pakistan Moeslim students reject the theory of evolution based on their religious beliefs, this indicates a low understanding of the theory of evolution (Barnes et al., 2021). Weisberg et al stated that conflict between religious beliefs and theory of evolution can reduce positive impact on acceptance and understanding of the theory of evolution (Barnes et al., 2021). Like Weisberg et al, Sinatra stated that individuals with strong religious beliefs have a negative impact on positive views of the theory of evolution (Kahyaoğlu, 2013). Brem et al stated that one of the factors related to the acceptance and understanding of theory of evolution is motivational and emotional barriers, these barriers seem to be based on negative perceptions of the theory of evolution based on personal and social life (Hanisch \& Eirdosh, 2020). Nadelson and Hardy; Barnes and Brownell; Hill, added the rejection of the theory of evolution is associated with social factors, such as culture, religious beliefs (Barnes \& Brownell, 2018). Smith stated that misconceptions about the theory of evolution are associated with religious beliefs (Yasri, 2014). Kampourakis and McCain (2016), that misconceptions do not only occur in biology college students, even misconceptions also occur in high school students and health students. Rosengren et al added that the poor understanding is related to various factors, including cognitive factor, epistemological, emotional, and religious beliefs (Torkar \& Sorgo, 2020).

Futuyma; Gould; Miller, stated that the scientific understanding about theory of evolution is very diverse and complex (Nadelson, 2009), Miller added, so it is not surprising that students orcollege students have incomplete knowledge (misconceptions) about the theory of evolution (Nadelson, 2009). Further, relate with the type of reasoning, conflict between religious beliefs with the theory of evolution and misconceptions about the theory of evolution, Kind and Osborne (2016) stated the one of the factors that influence the style of reasoning is content knowledge, which is content knowledge is knowledge of specific concepts in the specific domain, and becomes an ontological entity that is used for reasoning. Then the relation with content knowledge, referring to the principle of knowledge sharing, Lee; knowledge sharing is defined as the activity of transferring or disseminating knowledge from one person to another, to another group or organization (Yi, 2008), or Ipe stated that knowledge sharing is basically the act of making knowledge available to others (Yi, 2008). According to $\mathrm{Yi}$ (2008) that knowledge is transferred from knowledge providers to knowledge recipients, in this case the teacher as a provider of knowledge to students (recipients), so that one of the factors that causes misconception on the theory of evolution is the prior knowledge received by biology prospective teachers. Duman (2018) explains that the false of prior knowledge is continuously maintained by biology prospective teachers, causing him difficulty in accepting scientific concepts about the theory of evolution. 


\section{CONCLUSION}

Based on this finding, that the type of reasoning of biology prospective teachers is dominated by reasoning based on religious beliefs and intuitive reasoning, it indicates that there is a conflict between religious beliefs and the theory of evolution, and students do not understand the concepts of the theory of evolution. Referring to these findings and the opinion of experts that acceptance and understanding of the theory of evolution is influenced by various factors, such as knowledge of evolution, religious beliefs, and sharing knowledge. Then our concern is about religious beliefs, because this factor may be very difficult to change, but even so it becomes a challenge for us on how to integrate religious beliefs with the theory of evolution.

\section{RECOMENDATION}

Referring to the findings of Kampourakis and McCain (2016), and Yi (2008) about knowledge sharing, further research is recommended to examine the acceptance or understanding, and beliefs of teachers, both in middle and high schools on the theory of evolution.

\section{ACKNOWLEDGEMENT}

Thanks to the Ministry of Education and Culture, Research and Technology for financial support in completing this research through Decree No. 168/E4.1/AK.04.PT/2021.

\section{REFERENCES}

Abate, T., Michael, K., \& Angell, C. (2020). Assessment of scientific reasoning: development and validation of scientific reasoning assessment tool. EURASIA Journal of Mathematics, Science and Technology Education, 16(12).

Arthur, S. (2013). Evolution acceptance among pre-service primary teachers. Evolution: Education and Outreach, 6(20).

Barnes, M.E., \& Brownell, S.E. (2018). Experiences and practices of evolution instructors at Christian universities that can inform culturally competent evolution education. Wiley Periodicals, Inc.

Barnes, M.E., Dunlop, H.M., Holt, E.A., Zheng, Y., \& Brownell, S.E. (2019). Different evolution acceptance instruments lead to different research findings. Evo Edu Outreach, 12(4).

Barnes, M.E. Dunlop, H.M., Sinatra, M., Hendrix, T.M., Zheng, Y., \& Brownell, S.E. (2020). Accepting evolution means you can't believe in god": atheistic perceptions of evolution among college biology students. CBE-Life Sciences Education.

Barnes, M.E., Supriya, K., Zheng, Y., Roberts, J.A., \& Brownell, S.E. (2021). A new measure of students' perceived conflict between evolution and religion (PCoRE) is a stronger predictor of evolution acceptance than understanding or religiosity. CBE-Life Sciences Education.

Barnes, M.E., Roberts, J.A., Maas, S.A., \& Brownell, S.E. (2021). Muslim undergraduate biology students' evolution acceptance in the United States. Plos One.

Barz, D.L., \& Cadariu, A.C. (2016). The development of scientific reasoning in medical education: a psychological perspective. Clujul Medical, 89(1), pp. 32-37.

Bautista, J.S., Escobar, V.H., \& Miranda, R.C. (2017). Scientific and religious beliefs about the origin of life and life after death: validation of a scale. Universal Journal of Educational Research, 5(6), pp. 995-1007.

Bickmore, B.R., Thompson, K.R., Gandy, D.A., \& Tomlin, T. (2009). Commentary: on teaching the nature of science and the science-religion interface. Journal of Geoscience Education, 58(3), pp. 168-177. 
Cavojová, V., \& Ersoy, S. (2019). The role of scientific reasoning and religious beliefs in use of complementary and alternative medicine. Journal of Public Health, pp. 1-10.

Cebesoy, U.B. (2020). Investigating Turkish pre-service science teachers' moral reasoning in genetics related socioscientific issues. Journal of Science Learning, 4(1), pp. 20-30.

Cheryl-To., Tenenbaum, H.R., \& Hogh, H. (2017). Secondary school students' reasoning about evolution. Journal Of Research In Science Teaching, 54(2), pp. 247-273.

Coley, J.D., \& Tanner, K. (2015). Relations between Intuitive biological thinking and biological misconceptions in biology majors and nonmajors. CBE-Life Sciences Education, 14, pp. 1-19.

Coley, J.D., Arenson, M., Xu, Y., \& Tannner, K.D. (2017). Intuitive biological thought: developmental changes and effects of biology education in late adolescence. Cognitive Psychology, 92, pp. 1-21.

Ding, L., Wei, X., \& Mollohan, K. (2014). Does higher education improve student scientific reasoning skills?. Int $J$ of Sci and Math Educ.

Duman, N. (2018). Determination of misconceptions in disaster education with concept cartoons: the case of flood and overflow. International Journal of Environmental \& Science Education, 13(10), pp. 831-843.

Gafaell, J., Prieto, T., Abdelaziz, M., Alvarez, I., Anton, J., Arroyo, J., Bella, J.L., Botella, M., Bugallo, A., Claramonte, V., Gijon, J., Lizarte, E., Maroto, R.M., Megias, M., Mila, B., Ramon, C., Vila, M., \& Rolan-Alvarez, E. (2020). Acceptance and knowledge of evolutionary theory among third year university students in Spain. Plos One.

Hanisch, S., \& Eirdosh, D. (2020). Educational potential of teaching evolution as an interdisciplinary science. Evo Edu Outreach, 13(25).

Hokayem, H., \& BouJaoude, S. (2008). College students' perceptions of the theory of evolution. Journal of Research in Science Teaching, 45(4), pp. 395-419.

Kahyaoğlu, M. (2013). The teacher candidates' attitudes towards teaching of evolution theory. Necatibey Faculty of Education Electronic Journal of Science and Mathematics Education, 7(1), pp. 83-96.

Kampourakis, K., \& McCain, K. (2016). Believe in or about evolution?. BioScience, 66(3).

Kind \& Osborne, 2016). Styles of scientific reasoning: a cultural rationale for science education?. Science Education, XX(X), pp. 1-24.

Manwaring, K.F., Jensen, J.L., Gill, R.A., Sudweeks, R.R., Davies, R.S., \& Bybee, S.M. (2018). Scientific reasoning ability does not predict scientific views on evolution among religious individuals. Evo Edu Outreach, 11(2).

Nadelson, L.S. (2009). Preservice teacher understanding and vision of how to teach biological evolution. Evo Edu Outreach.

Opitz, A., Heene, M., \& Fischer, F. (2017). Measuring scientific reasoning - a review of test instruments. Educational Research and Evaluation, 23, pp. 78-101.

Osterhaus, C., Koerber, S., \& Sodian, B. (2020). The science-P reasoning inventory (SPR-I): measuring emerging scientific-reasoning skills in primary school. International Journal of Science Education.

Richard, M., Coley, J.D., \& Tanner, K.D. (2017). Investigating undergraduate students' use of intuitive reasoning and evolutionary knowledge in explanations of antibiotic resistance. $C B E$ - Life Sciences Education.

Saad, M.I., Baharom, S., Mokshien, S.E., \& Setambah, M.A. (2017). Factors affecting reasoning skills on socio scientific issues (SSI). International Journal of Academic Research in Business and Social Sciences, 7(2). 
Setambah, M.A. (2018). Measurement model of reasoning skills among science students based on socio scientific issues (SSI). Indonesian Research Journal in Education (IJRE), 2(1).

Torkar, G., \& Sorgo, A. (2020). Evolutionary content knowledge, religiosity and educational background of Slovene preschool and primary school pre-service teachers. EURASIA Journal of Mathematics, Science and Technology Education, 16(7).

Yasri, P. (2014). A systematic classification of student misconceptions in biological evolution. International Journal of Biology Education.

Yi, J. (2008). A measure of knowledge sharing behavior: scale development and validation. Knowledge Management Research \& Practice, 7, pp. 65-81.

Zulkipli, Z.A., Yusof, M.M., Ibrahim, N., \& Dalim, S.F. (2020). Identifying scientific reasoning skills of science education students. Asian Journal of University Education (AJUE), 16(3). 